Canadian University Music Review

Revue de musique des universités canadiennes

\title{
Carl Dahlhaus. Studies on the Origin of Harmonic Tonality. Translated by Robert O. Gjerdingen. Princeton: Princeton University Press, 1990. xv, 389 pp. ISBN 0-691-09135-8
}

\section{Paul Cadrin}

\author{
Numéro 14, 1994
}

URI : https://id.erudit.org/iderudit/1014318ar

DOI : https://doi.org/10.7202/1014318ar

Aller au sommaire du numéro

\section{Éditeur(s)}

Canadian University Music Society / Société de musique des universités canadiennes

\section{ISSN}

0710-0353 (imprimé)

2291-2436 (numérique)

Découvrir la revue

Citer ce compte rendu

Cadrin, P. (1994). Compte rendu de [Carl Dahlhaus. Studies on the Origin of Harmonic Tonality. Translated by Robert O. Gjerdingen. Princeton: Princeton University Press, 1990. xv, 389 pp. ISBN 0-691-09135-8]. Canadian University Music Review / Revue de musique des universités canadiennes, (14), 188-210. https://doi.org/10.7202/1014318ar

All Rights Reserved (C Canadian University Music Society / Société de musique des universités canadiennes, 1994
Ce document est protégé par la loi sur le droit d'auteur. L’utilisation des services d'Érudit (y compris la reproduction) est assujettie à sa politique d'utilisation que vous pouvez consulter en ligne.

https://apropos.erudit.org/fr/usagers/politique-dutilisation/ 


\section{REVIEW ESSAY}

Carl Dahlhaus. Studies on the Origin of Harmonic Tonality. Translated by Robert O. Gjerdingen. Princeton: Princeton University Press, 1990. xv, 389pp. ISBN 0-691-09135-8

It is hard to disagree with the claim, printed on the jacket of this book, that "Carl Dahlhaus was without doubt the premier musicologist of the postwar generation." He is an impressive model for the profession, both for the wealth of topics he approached and for the thoroughness with which he broached the most perplexing issues. The prospect of writing a critical review of a significant work by an author of this stature is daunting, would it be merely for the level of scholarship displayed on every page. This book addresses issues that are so central to every domain of musicology that to greet it with servile deference would be just as unprofessional as dismissing it with the back of one's hand as outdated. Thus what should have been a straightforward book review has grown into an article-length essay.

Not only are the issues approched vital to us all, they are also treated by the most eminent spokesperson of an intellectual tradition standing at the core of German music-theoretic life. Dahlhaus is whole-heartedly, but very clearmindedly, a follower of Riemann, and this book is a most exhaustive verification of the historical limits of the latter's theory of harmonic tonality. While recent publications may point to a resurgence of interest in Riemann's theoretical work on our continent, its current influence on North American academia pales in comparison with the sustained prestige it enjoys in central Europe, in particular in the teaching of harmony. Our vantage point is that of North American theory of the 90's, impressed as it is with Schenkerianism and with Schoenberg's theory of harmony. In our perspective, the attention granted by Dahlhaus to these two authors is less than satisfactory (barely 36 lines are devoted to Schenker, and Schoenberg's classification of chord progressions is dispatched in two sparse footnotes). This discrepancy between an almost exclusive reliance on Riemann, on the one hand, and a lack of interest in Schenker and Schoenberg, on the other, is revealing of the abyss separating the intellectual tradition to which this book belongs from ours. It is also a yardstick of the challenges awaiting the North American reader of this translation.

Following a short introduction, the book is divided into four chapters: 1 . The theory of harmonic tonality; 2 . Intervallic and chordal composition; 3 . Mode and system; and 4. Analyses. The first chapter is essentially polemical, extensively discussing the theories of Fétis (the father of the concept of tonality), Rameau, 
and Sechter, as read in the light of Riemannian concepts. The second chapter deals with the transition from the intervallic approach to composition prevalent in the Middle Ages to the chordal approach of thoroughbass harmony. This chapter is by far the most extensive and most impressive in terms of scholarship -the notes alone extend over 26 pages! Equipped with his unique mastery of both the repertoire and the literature, Dahlhaus relentlessly chases misconceptions, most of which are to be ascribed to anachronistic readings either of the music or of the theory. The third chapter follows the development of the tonal system, trying to pinpoint the historical moment when the modal system has definitely been displaced, again carefully dodging the pitfalls of anachronism. While the book is well worth reading just for its wealth of musical examples, the process is reversed in the final chapter: rather than illustrating theoretical problems with the analysis of ad hoc examples, Dahlhaus scrutinizes three representative and homogeneous repertoires (motets by Josquin, frottolas by Cara and Tromboncino, and madrigals by Monteverdi) from a variety of angles. This comprehensive approach is open-ended in more than one way: a number of issues are raised which had to be ignored in previous chapters, and many questions are left unanswered.

Given the polemical nature of much of the first chapter, on the one hand, and the speculative nature of the present commentary, on the other, the order in which topics are dealt with by Dahlhaus must be revised. Clarifications about basic concepts such as tonality, modality, harmony, and the "natural" foundation of the tonal system are first to be sought throughout the book. The basic tenets of the theory of functional harmony as understood by Riemann/Dahlhaus are then examined. Only at this point will it be possible to ponder the polemics raised by the author in the first chapter, particularly those against Fétis and Rameau.

\section{Basic Concepts: Tonality, Modality, and Harmony}

\section{Tonality and Modality}

Early in the book, Dahlhaus, following Riemann, establishes the conceptual primacy of the chord over the individual tone in establishing tonality:

According to Riemann, tonality is a system of chords or "harmonies." The thesis of the primacy of the chord vis-à-vis the individual tone, and of the chordal context vis-à-vis the scale, is one of the founding principles of the theory of functions. (p. 10)

However, Dahlhaus unmistakably dissociates himself from Riemann when he 
considers the concept of tonality to be mutable:

If confusion is to be avoided, one must differentiate "melodic" tonality from "harmonic" tonality. Relationships among tones need not be reducible to chordal contexts in order to fall under the concept of tonality. (p. 17)

The consequences of this relativistic attitude seem to have escaped Dahlhaus's attention. The reader of this essay should become aware of the fact that, in spite of the fascination of its logical elegance, Riemann's system is an oversimplification when used to account for the language of so-called "tonal" music, an oversimplification that does not stand up to a mollification of its basic principles. Because of his basic loyalty to the Riemannian view of tonal music, however, Dahlhaus draws an account of the theory and practice of pre-tonal music that is entirely admirable for its sensitivity to the finest historical and analytical nuances.

We theorists are always reluctant to use the words "modal" and "tonal" in order to characterize the compositional techniques of different eras because we are sensitive to the fact that, strictly speaking, modal music is "tonal," on the one hand, and, on the other, tonal music is always "modal." Although he expounds upon this paradox at great length, Dahlhaus ends up vindicating the conventional terminology:

The tonality defined by melodic categories, which preceded the chordally based, harmonic tonality of the 17 th century, can be defined as "modality." And, when intended as the opposite of "modal," it may be permissible to shorten the expression "harmonically tonal" to just "tonal." The concept of "tonality" therefore not only encompasses that of "modality", but can also become its opposite. (p. 17)

To those who expected to find in this book an illuminating solution to this enigma, these lines come as a disappointment.

Further in the book, the author gives up any hope of defining the term "modal" with any accuracy: "Mode' is a historical concept that resists definition as a fixed cluster of features" (p. 192). Fortunately his disheartenment proves to be passing since he does provide a carefully circumscribed clarification a hundred pages later:

"Mode," as a category of polyphony, is a concept that embraces melodic formulas, schemata for imitations, the ambitus of each voice, and disposi- 
tions of cadences. But it includes no norms or models for the sequence of chords. (p. 291)

Tonality, understood in the historical sense of "harmonic tonality," does include such norms for the sequence of chords:

Tonal harmony rests on two assumptions: first, that a triad constitutes a primary, direct unity; and second, that the progression of chordal roots establishes the key. (pp. 3f)

In Dahlhaus's perspective, therefore, the difficulty with defining "modal" music stems from the fact that it is characterized by a range of parameters belonging to different levels of structure. On the other hand, it is relatively easy to define what makes a piece of music "tonal" according to Riemann: the prevalence of the triad and of key-defining root progressions should be sufficient for that purpose.

\section{Harmony}

The word, "harmony," has known more than its share of vicissitudes in the course of history:

In music, the concept of harmony has included, since the early Middle Ages: (1) the combining of tones into a sequence of tones, or even groups of tones into a melody; (2) the agreement of the two tones in a dyad, or of the tones and intervals in a triad; (3) the connecting of dyads into an intervallic progression; (4) the relationship among the voices of a polyphonic composition; and (5) the joining together of chords into a chord progression. (pp. 18f)

Under (2), Dahlhaus could have extended his enumeration to chords of four and more notes: the seventh of a four-note chord is considered by traditional textbooks as "part of the harmony" when compared with other dissonances (e.g., suspensions), not to mention those more recent styles in which five-note or even six-note harmonies are the norm.

Tonal harmony is "dynamic." A tension exists between chords with subdominant and dominant function, a tension that presses toward resolution in the tonic. This tension can be more clearly expressed with dissonances the sixth above the subdominant triad and the seventh above the dominant 
triad - but it is not based on them. Apart from sporadic cases, 16th-century music lacks the functional tensions that constitute the essence of tonal harmony. (pp. 239f; italics mine)

When the chord of the dominant carries a seventh or follows the subdominant, an impulse to move to the chord of the tonic does exist, but this tension is not inherent in the triad of the dominant. It is a result of the appearance of the tritone, either heard simultaneously when the seventh is present, or in close proximity (the "false relation") when this chord is preceded by a chord containing the subdominant. The generalization of this "tension," in particular its application to the subdominant, is a consequence of the interpretation of harmonic motion as a backward extension of the cadence, a Riemannian concept which will be dealt with later on in this essay. In my view, it is a myth. Is there such a thing as a "tension" compelling the composer to leave the initial tonic chord? Were this phenomenon of "tension" the decisive factor of musical motion that Dahlhaus (and many others) would like it to be, it would exist there in the first place, otherwise there would never be any reason for moving to a second chord! In fact, there is no more "tension" inherent in the subdominant triad (when it is consonant) than in the initial tonic. What exists is a feeling of mutual complementarity arising when the subdominant chord is heard after the tonic chord. This feeling of mutual complementarity is a result of their proximity understood in terms of common pitch classes and conjunct voice-leading, two points that will be developed further in this article. Only a posteriori can one interpret this connexion as involving the existence of a "tension" in the first chord, a tension fulfilled by the appearance of the second chord. Indeed, in the absence of revealing dissonances, the tonic-subdominant pair per se is open to interpretation as dominant-tonic in the key of the subdominant. When followed by the legitimate dominant, the ambivalence is removed. By and of itself, the tonic-subdominant succession only weakly defines tonality. Only in the dominant can one speak of a palpable "tension" calling for resolution to a specific tonic, again as a result of the appearance of the tritone.

Confirmation of this point of view may be found in the existence of the deceptive cadence, substituting for the authentic cadence. This familiar process of substitution does not apply to the plagal cadence. Resolving the dominant to a chord other than the tonic generates a feeling of "deception" because the tension inherent in the dominant is only partially relaxed by the deceptive cadence. Since no such tension exists in the subdominant, it cannot be deprived of a proper resolution by an allegedly deceptive substitute.

These sketches of the book's three basic concepts (tonality, modality, and harmony) are to be taken with all due caution, a full clarification involving the quotation of extensive sections of the book. Provisionally equipped with these, 
however, we are in a position to deal with a broader issue which Dahlhaus himself considers problematic to this day: "whether a 'natural' foundation of harmonic tonality is possible ..." (p. 14).

\section{The Search for a "Natural" Foundation to the Tonal System}

Since Rameau, music theorists have relentlessly probed the data of acoustics, and their application to tuning systems, in order to find a "natural" foundation for the tonal system. Dahlhaus vigorously and repeatedly fights that obsession:

The equation of tonal system with tuning is unsupported: a tonal system can appear in several tunings and, conversely, a tuning in several tonal systems. (p. 187)

One can say without exaggeration that the system of tonal harmony is acoustically a fiction, since there is no conceivable tuning that would do complete justice to it. (p. 189)

According to Dahlhaus, this fascination with tuning systems is to be held responsible for regrettable historical delays in the investigation of the tonal system:

As long as it was a dogma untainted by skepticism that the mathematical determinations of intervals were not measurements extrinsic to music but direct expressions of its essence, the thought of an irreconcilable divergence between musical meaning and acoustical representation could never arise. (p. 190)

The fact that the theorists misunderstood and indeed had to misunderstand the difference between tonal system and tuning resulted in the mathematical determination of the intervals being unceasingly investigated while the structure of the tonal system, whose difference from its acoustical exterior went unnoticed, was never examined. (p. 191)

A natural foundation for the system must be found, not in the nature of sound, but in the nature of the human mind. On this, Dahlhaus quotes Riemann extensively:

The fundamental idea of Hugo Riemann's theory of functions is "that the act of listening to music is not a passive sufferance of the effects of sound on the organ of hearing, but is much more a highly developed application of the logical functions of the human mind... . The inductive method of the physiology and psychology of music proceeds down the wrong road if it 
takes as its point of departure the investigation of the elements of music as sound, instead of the establishment of the elements of music as conceptualized in the mind." (p. 47; quoted from Hugo Riemann, "Ideen zu einer 'Lehre von den Tonvorstellungen'," Jahrbuch der musikalischen Bibliothek Peters, 21/22 [1914/1915]: 1-2)

Since he assumes the operations of the human mind to be just as unchangeable as the laws of acoustics, Riemann would certainly disagree with Dahlhaus in his search for historical limits to the laws of tonality:

Both the theory of fundamental progressions [Sechter] and the theory of functions were conceived as "natural systems," not as dogmas. Hence the search for criteria on which to base a historical determination of the origin of tonal harmony violates the very intentions at the root of these theories. (p. 63)

On this issue, Dahlhaus sides with Helmholtz rather than with Riemann. Commenting on the famous passage where the father of modern acoustics explains why musical systems vary culturally and historically, he writes:

While Riemann the historian believed that the basic principle of the system of harmony could be found in nature, Helmholtz the natural scientist looked to history. (p. 59)

Being a scientist, Helmholtz could not cultivate a reverential fear of the laws of acoustics: he knew perfectly well their origin as well as their limits. Such was not the case with Riemann. Dahlhaus could well have applied to the latter a statement he makes about von Herzogenberg: "A generation that had grown up in awe of the natural sciences viewed with suspicion the realization that musical tone relationships could not be reduced to the given acoustical data" (p. 47). In spite of this illuminating observation, it is to historians and ethnologists that Dahlhaus grants credit for recognizing the historical limits of the system:

So "tonality," the phenomenon whose theory Riemann had developed, had to be more narrowly defined as "harmonic tonality" and removed from other types de tonalités. And in consequence, Riemann's "tonality" became a historical phenomenon whose origin could be described. (p. 3)

Of all the stumbling blocks created by Riemann's overreliance on acoustics, the problems raised by the minor triad and the minor mode are the most critical. 
"For the theory of functions, the phenomenon of the major-minor analogy is a "blind spot"' (p. 56). The recent development of set theory as an analytical tool has opened up new vistas by displacing the conceptual focus from acoustics to interval content, certainly a more fruitful approach than the elusive metaphors inspired by the harmonic series.

\section{The Elements of Tonal Music in a Riemannian Perspective}

The basic elements of the language of tonal music, in a Riemannian perspective, are, on the one hand, chords per se, and, on the other, motion between chords (harmonic motion). The latter element is subsumed under the general principle of the "backward extension of the cadence," hence the need of a careful examination of what is a cadence. Four subsidiary concepts must be examined under this heading: the "forgotten" tritone; the opposition between intervallic and chordal composition; the problematic subdominant; and the question of harmonic rhythm.

\section{Chords}

Defining the conditions under which chords are identified is of primary import in the definition of their properties and operations. Since Rameau, the principle of octave equivalence is systematically applied to pitches in order to group them into chords, the technique of inversion being the most obvious application of this principle. On this, Dahlhaus writes lines which will come as a surprise to many readers, particularly those who have had some experience with teaching elementary theory:

The theory of tonal harmony does not assert that we are constrained to hear the tone [a sixth above the bass] as the root of a sixth chord owing to acoustical or perceptual laws, but only that the concept of inversion makes possible a theoretical representation of the chordal relationships within the system of tonal harmony. (p. 68)

In my view, this statement imperils the very basis of the system, grounded as it is in the psychology of perception. The only value Dahlhaus sees to the principle of inversion is the fact that it makes possible the system of chordal relationships as understood in the theory of harmony. Were his view correct, any application of it to the repertoire, even in a historically limited way, would be pointless. Indeed, this theoretical representation would be nothing more than an accidental 
by-product of the fact that chords are reducible to stacked-up thirds, a simple application of the principle of octave equivalence.

Obviously Dahlhaus would disagree with those who think that the processes involved in making sense out of tonal music are at stake here. Beginners may be allowed to think that chord inversions are nothing more than abstract concepts, but we certainly all cherish the hope that, under our guidance, our students will develop the ability to grasp them and will then be convinced of their concrete character. In a field of applied knowledge such as music theory, a learning process can be said to be successful when the system has become part of the immediate experience of the learner. In the case of chord inversions, this happens when the listener is able to focus his attention on those ingredients of the acoustical content of music which grant chords their particular status within the inversion scheme (the interval of the fifth in root position; the sixth in first inversion; etc.). As is the case with the sounds of a new language, mastering this process involves making it part of the learner's immediate perceptual experience. Once acquired, it is not felt to be the outcome of a process of abstraction anymore.

What use would we have for a purely theoretical system of the kind that Dahlhaus seems to advocate? The history of music theory is a graveyard of systems which have come and gone without leaving any trace simply because their authors were more intent on pushing their theories through their ultimate logical ramifications than on accounting in a significant way for musical experience. The continuing success of Rameau's concept of inversion is a testimony to the fact that, for most musicians of academic persuasion, it accounts effectively for an important aspect of their aural experience of tonal music.

Misconstrued applications of Rameau's principles all too often sadly distort their significance, in particular when chords are identified as "inversions" when the listening experience points in another direction. We are all familiar with the case of the cadential $6 / 4$ chord, which can be analyzed as a second inversion only by ignoring the fact that the alleged root carries all the trappings of a dissonant non-chord tone. If this is what Dahlhaus had in mind when he wrote the lines quoted above, then I have to agree with him that "inversions" are "purely theoretical representations." However, if a more careful application of the principle of inversion is adopted - an application that comes closer to the actual aural experience of the repertoire, then, far from being a "purely theoretical representation," as Dahlhaus would like it to be, it is part and parcel of the discrimination processes involved in making sense out of tonal music.

Further in the book, Dahlhaus the musician comes very close to challenging the position of Dahlhaus the theorist: 
As sonorities, the intervals differ in their degree of "stability" or "instability," a factor independent of the stylistic difference between modal counterpoint and tonal harmony. A minor third has a more "unstable" effect than a major third, and the lower tone is a weaker root in the minor third than in the major third. The precedence of the bass tone, undisputed in the major triad, in the minor triad is exposed to the competition of the middle tone, the "root" of the major third. But the fact that the third of the minor triad appears as a "second root" is not without some bearing on the meaning of the sixthree chord: the minor six-three chord is an inversion of the root-position chord to a lesser degree than is the major six-three chord.

While the differentiation is unmistakable as a phenomenon in tonal harmony, it is irrelevant for the "harmonic logic." One can ignore the fact that the six-three chord $\mathrm{f}-\mathrm{a}-\mathrm{d}$ ' is not a completely equivalent variant of the root position chord d-f-a because the difference has no effect on the six-three chord fulfilling the same function as the root-position chord. (p. 236)

While agreeing entirely with the first paragraph, I must object very strongly to the second. Root position triads are indeed singled out for specific functions in the musical discourse, noticeably in cadential contexts, where first inversions are not considered to be appropriate. To write that "the difference has no effect on the six-three chord fulfilling the same function as the root-position chord" is to me a clear instance of circular thinking. If "function" here is simply understood to mean "belonging to the pitch class set $\mathrm{D}, \mathrm{F}, \mathrm{A}$," then the conclusion is foregone, and the differentiation between root position and inversion indeed is irrelevant. However, if functionality is understood as including the logical role played by a chord as conditioned by its position within a given succession, then the sixthree chord is never completely interchangeable with its root position cousin.

\section{Harmonic Motion}

The empirical knowledge underlying the theory of functions can be expressed most simply by the proposition that chords at the interval of a fifth or second are functionally different, while chords at the interval of a third are functionally similar. (p. 58)

Had Dahlhaus further scrutinized this informal classification of chord motions, he would have ended up adopting a system very similar to that of Schoenberg, which he rejects elsewhere. What is the basis for this "difference" or "similarity" of chord functions? 
In a context where octave equivalences are systematically applied to verticalities, harmonic motion is exclusively a function of the pitch classes involved and cannot be anything else: "difference" is achieved by the displacement of pitch classes, while "similarity" is a result of shared pitch classes, regardless of melodic motions to different registral positions. With respect to their rate of harmonic motion, triadic chord progressions are thus classified into: stasis (same pitch classes); minimal motion (only one pitch class change - root motion by third); average motion (only one pitch class in common - root motion by fifth); and maximum motion (every pitch class is displaced - root motion by second). This classification certainly comes closer to that proposed by Schoenberg than to Riemann's, but it is the only one apt to survive the generalized application of the principle of octave equivalence. Root motion by fifth enjoys a certain degree of prevalence in diatonic harmony because it yields a middle-of-the-road sense of harmonic motion, against which other intervals of root motion contrast, either in the direction of intensification (root motion by second) or in the direction of relaxation (root motion by third).

\section{The Cadence}

The Riemannian system is based on the paradigmatic progression I-IV-V-I, explicitly understood as a retrograde extension of the V-I cadence:

In the theory of functions, taking different chords to be the same thing is an expedient meant to render feasible the reduction of chord progressions to the cadential model of tonal harmony. (p. 88)

Nowhere does Dahlhaus raise the fundamental question: what is a cadence? A cadence is a punctuation. It is a way of telling the listener that a unit of meaning has ended, or, more accurately, a way of forewarning the listener of an impending ending. Clearly, one does not expect this portion of the message to carry much new or original information. By its very nature and purpose, a cadence must be more conventional and redundant than the message it concludes. To restrict the tonal system to an extension of the cadence is to focus on those properties of the musical language that are the most trivial and carry the least significant elements.

A cadence must be marked both by comprehensible relationships and by clear distinctions. In the parallel cadence of the 14th and 15th centuries, the connecting factors were the half- and whole-step linkages and the "tendency" of dependent, imperfect consonance to move toward perfect consonance. The disconnecting factors, on the other hand, were the sonorities' contrasting characters, the lack of a common tone, ... and the "inner 


\begin{abstract}
distance" between tones a whole step or half step apart. The V-I cadence is relatively poor in terms of such properties. The wide "external distance" between the roots has a differentiating effect, while in addition to a common tone, the fifth-relation and the leading tone establish coherence. The contrary motion of the dominant's third and fifth to the tonic's root - as the discant-tenor clausula, the prerequisite to, and origin of, the V-I cadence becomes superfluous and a matter of indifference in tonal harmony. (pp. 93-94)
\end{abstract}

Following Rameau, one must ackowledge that, in music of the tonal period, the paradigmatic form of the chord of the dominant includes the seventh, the simple dominant triad being relegated to the status of an incomplete chord. Within this context, the motion from tritone to imperfect consonance inherent in the $\mathrm{V}$-I root progression is the exact counterpart of the motion from imperfect to perfect consonance characteristic of pre-tonal music. In the latter type of cadence as in the former, contrary motion by step and half-step predominates.

To write that "contrary motion ... becomes superfluous and a matter of indifference in tonal harmony" is a deplorable oversimplification. Were this statement correct, cadences such as the one shown in example 1 would proliferate in music composed after 1600 . They don't! In fact, voice leading of this type does not appear before the early 20th century, precisely at a time when the entire system of tonal music is shaken to the ground. Chromatic progressions difficult to integrate within the triadic framework of functional tonality, but coherent from the point of view of voice-leading (the augmented sixth in "root" position or the famous "Tristan" chord are good cases in point) will have become part of current practice long before this theoretically legitimate dominant-tonic progression ever makes its appearance in actual music. One can only conclude that the rules of voice-leading which are violated in this example carry more weight in explaining the perceived coherence of a V-I chord progression than root

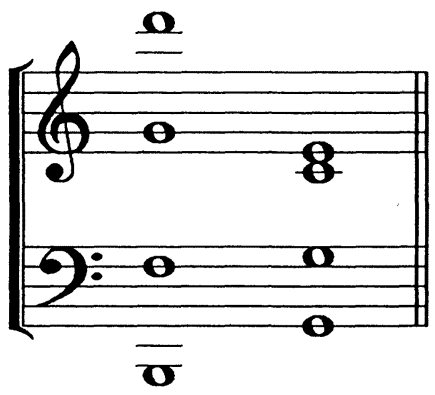

Example 1. Atypical cadence without resolution of tritone by contrary motion. 
motion as understood in the theory of functional harmony. Indeed, motion from imperfect to perfect consonance has simply been removed one step away to motion from tritone to imperfect consonance, but the basic principle of cadential voice-leading effective in Medieval and Renaissance music, namely contrary conjunct motion from a relatively less consonant interval to a more consonant one, is indeed still observed by Wagner and Brahms.

Voice-leading techniques have certainly been expanded in the tonal period through the widespread use of delayed and indirect resolutions (characteristic of the prevalent instrumental styles) but never to the extent of becoming "indifferent," as Dahlhaus would like them to be. In his "Guide to the terminology of German harmony," in the preliminary pages of the book, Robert $\mathrm{O}$. Gjerdingen underlines the fact that, within the Riemannian system,

a sequence of $\mathrm{A} b$-major, $\mathrm{B} b$-major, and $\mathrm{C}$-major chords, for example, could be neatly interpreted as a subdominant (sP) to dominant (dP) to tonic $(\mathrm{T})$ progression in $\mathrm{C}$-major, a reading of these chords not without support in certain late-Romantic cadences. (p. xiii)

Indeed one can easily find examples of this progression fulfilling cadential purposes in the repertoire of the first half of our century, but in every single instance that I have ever come across, contrary conjunct motion is the rule. One can only infer that contrary conjunct motion is a privileged feature of cadential processes from the earliest days of polyphony to the beginning of our century. While allowing for interesting but abstract generalizations within the theory itself, the so-called principle of "indifference" of linear motion in tonal music critically impoverishes our understanding of the perceivable logic of compositional practice.

\section{The Case of the Forgotten Tritone}

Dahlhaus's disregard for the significance of the tritone and its incumbent voiceleading becomes more apparent in his avowed powerlessness to explain the "forbidden" progressions of conventional harmony:

The progressions V-ii (D-Sp), iii-IV (with the meaning Dp-S and not Tl$\mathrm{S})$, and iii-ii (Dp-Sp) - just like V-IV - are all avoided. It is difficult to give sufficient reasons for the rule. (p. 65; italics mine)

Sorry, Herr Doktor Professor Dahlhaus! There is a simple, and sufficient, explanation for this prohibition. All these chord progressions involve hearing the fourth degree AFTER having heard the leading tone. The underlying rule is that the tritone is never left dangling. The pitch, F, may be heard before or together 
with B, but never after. Thus, the only interval allowed to follow B-F is C-E. Any other voice-leading avoids resolving the tritone, hence its undesirability in "strict" harmony.

\section{Intervallic versus Chordal Composition}

Dahlhaus repeatedly and energetically affirms the phasing out of intervallic composition with the advent of the chord-oriented tonal language. "'Interval progression' is a concept contrary to the categories of both linear counterpoint and tonal harmony" (p. 70). We must be grateful to Schenker for rehabilitating the importance of intervallic progressions, especially with his concept of chords of contrapuntal origin. Dahlhaus does hint at the possibility of such creatures but considers them to be vestiges of the previous era, while vigorously pleading elsewhere for the recognition of "passing chords": "Vestiges of interval progression without chordal roots survive in a tonal harmony and pose difficulties for its theory" (p. 70).

Dahlhaus's rejection of interval progressions in tonal music surfaces in contexts other than his discussion of cadences. Here is a good case in point:

Little can be be gleaned from the terminology of theorists since even in the 17 th and 18th centuries they had not renounced the term "imperfect consonance," though it had long since been debased from an expression that denoted the essence of the thing to a mere classificatory concept. (They needed it to formulate the proscription of hidden parallels.) (p. 186)

The classification of consonances as perfect or imperfect is at the core of every counterpoint treatise since the sixteenth century, and we remind the reader that the study of counterpoint was identified with that of composition itself well into the 19th century. This classification is essential not only "to formulate the proscription of hidden parallels," but also to understand the classification and operation of the various types of cadences as well as the proscription of parallel motion of perfect consonances (as distinct from that of imperfect consonances). In fact this classification permeates every aspect of so-called harmonic thinking. The various roles ascribed to chords based on their position or inversion are strict extensions of the uses ascribed to consonances based on their degree of perfection.

\section{Tonal Functions: The Problematic Subdominant}

In the prototypal I-IV-V-I phrase, the problematic chord, with Riemann as with every other theorist since Rameau, is the second one: 
One might ... try looking for the meaning of the term "subdominant" in those features or relationships common to all chords having a subdominant function.

The expectation is quickly disappointed, of course, that a recurring tone might form the vinculum substantiale [material link] between all chords that fulfill or could fulfill the subdominant function in a certain key. (p. 54)

Dahlhaus, following Riemann, appears to have been ensnarled in his own net. In its most rudimentary form, the harmonic phrase is a simple alternation of tonicdominant-tonic. Elaborating this simple pattern calls for the introduction of a third chord which we shall call the "pre-dominant" (the term "subdominant" being avoided here for obvious reasons). With very rare exceptions in music of the tonal period, this extra chord appears between the initial tonic and the dominant. It fulfills a double purpose: 1) to displace the tonic as the functional root (in order for harmonic motion to be heard with respect to the previous chord); 2) to delay the appearance of the dominant or, more specifically, of any chord carrying the leading tone (in order for harmonic motion to be heard with respect to the following chord). Any chord fulfilling this double condition is a legitimate candidate to the function of pre-dominant. Most of these chords do include the fourth degree, but not all of them, hence the disappointment experienced by Dahlhaus in looking for a tone common to all chords representative of the pre-dominant function.

Dahlhaus's disappointment is all the more surprising in that, a few pages later, he hints at the explanation sketched here:

The subdominant and subdominant parallel are functionally equivalent because both, owing to functional differences, contrast with not only the tonic but also the dominant, and therefore represent a third function. (p. 58)

\section{Harmonic Hierarchy and Rhythm}

Very late in the book, Dahlhaus introduces the concept of harmonic rhythm and the attendant hierarchy of harmonic functions:

The importance of harmonic rhythm is proved negatively by the phenomenon of the "passing chord." In a group of four $3 / 4$ or $4 / 4$ measures, measures whose harmonic content is shaped by the chordal functions S-TD-T, a third-inversion dominant chord on the last beat of the subdominant measure appears as a passing chord whose dominant function is only weakly characterized. 
[e.g., IV-V $\mathrm{V}_{2}^{4} / \mathrm{I}^{6}-/ \mathrm{V}_{3}^{4}-/ \mathrm{I}$ - ]

Since the chord is between the subdominant and the tonic, and thus "regular," its passing character is inexplicable as long as the harmony is studied separately. To comprehend why this chord appears as a passing chord, one that can be disregarded in a harmonic analysis, it is necessary to consider the formal function of harmony in creating relationships between comparable parts. The chord is perceived as a passing chord because taking it literally as a harmonic function would disturb the harmonic rhythm. (p. 308)

Comparing modal and tonal music from the vantage point of the hierarchization induced from harmonic rhythm would certainly yield fresh and interesting insights. One would even be tempted to go so far as to hypothesize that, in the quest for an explanation to the differences between these two languages, there lies a more promising lode than the elusive and disappointing opposition between intervallic and chordal composition. Similarly, the connection between the hierarchical character of functional harmony, on the one hand, and the repetitions and symmetries of tonally based music, on the other, would well be worth comprehensive substantiation in the repertoire. It is granted but passing attention by Dahlhaus (see p. 318).

\section{Dahlhaus on Fétis and Rameau}

\section{Fétis}

Rosalie Schellhous's brilliant article, "Fétis's Tonality as a Metaphysical Principle: Hypothesis for a New Science" (Music Theory Spectrum 13, no. 2 (Fall 1991): 219-40), is required reading for anybody interested in this topic. However, since she makes only passing reference to the book under scrutiny here, we must examine Dahlhaus's position more closely. Very fittingly, Dahlhaus enumerates the points of divergence between Fétis and Riemann. They are to be found:

[1.] in the intellectual tradition in which the category "tonality" is based;

[2.] in the designation of tonality's constituent features;

[3.] in the conception of the relationship between the system of chords and the underlying scale;

[4.] in the determination of the theory's range of validity. (p. 7)

However, Dahlhaus seriously misrepresents Fétis when he interprets the latter's characterization of tonality as a "purely metaphysical principle" with this 
parenthetical note: "by 'metaphysical' Fétis means 'anthropological"' (p. 8). As noted by Schellhous, "Since the earliest philosophical writings, the word metaphysics has been understood and used differently by different philosophers" (Schellhous, p. 228). Fétis uses this word both in its etymological sense and in its philosophical sense. In its etymological sense, it means "beyond the physical world," the "physical world" being here unequivocally identified with nature ("La nature ne fournit comme éléments de la musique qu'une multitude de sons..." [p. 8; quoted from François Joseph Fétis, Traité complet de la théorie et de la pratique de l'harmonie, 2nd ed. (Brussels and Paris, 1844\}, 11f].). In Fétis' view, the metaphysical dimension of the world includes the intellect, sensitivity, the mind, emotions, sentiments, and ideas. The relationships from which tonality emerges do not exist unless they are perceived by a human mind. Nothing in the physical world imposes a particular pattern to these relationships, their existence being strictly a result of mental operations.

They are no less necessary, however. These are ontological relationships (metaphysical in the philosophical sense), which are just as objectively real and necessary as physical relationships. The word "necessary" as used by Fétis carries the full strength of its philosophical implications: it is of the essence of those relationships to generate tonality. As with everything that is properly human, the ability to perceive these relationships is acquired through education ("Nous concevons cet ordre et les phénomènes mélodiques et harmoniques qui en découlent par une conséquence de notre conformation et de notre éducation" [p. 8; quoted from Fétis, p. 249].). The perception of these relationships is conditioned by education and cultural history and varies accordingly, but the very existence of the relationships is not a matter of education - it is an ontological principle. According to Fétis, the conventions of tonality may change, but the fact that a musical utterance generates tonal relationships of a certain kind is not a matter of conventions.

\section{Rameau}

Given the role played by Rameau in the history of harmonic theory, it is fitting that Dahlhaus should grant his ideas extensive coverage. His understanding of the French theorist appears to be lacking, however, and on three issues of cardinal import at that: the very existence of a principle basic to the entire system; the related concepts of dominante and sous-dominante; and the assessment of harmonic functions.

\section{a. Rameau's Basic Principle}

Rameau's system stems not from a rigid axiom, but from the notion that tonal harmony is based on the correlations between the resolutions of 
dissonance, the progressions of the fundamental bass, the meanings of chords, and the scale degrees of a key.... The essential feature of his system is the correlation of factors and not their unfolding from a single principle. (p. 24)

This is highly unfair to Rameau, who deliberately evolved his system from a single source: the numerical proportions of string lengths in the Traite of 1722 and the pitches of the harmonic series in subsequent writings. (Dahlhaus hints at these two sources in the first lines of p. 40.) Everything, from chord construction to the treatment of dissonances, is deduced from one of these two principles. If Dahlhaus were right, Rameau's lifelong efforts would betray a severe case of stubborn personal delusion.

\section{b. The Related Concepts of dominante and sous-dominante}

Hence Rameau defines the dominante and sous-dominante not primarly in terms of tonality, but in terms of compositional technique - as chordal types requiring a specific resolution of dissonance and a corresponding progression of the fundamental bass. (p. 26)

Rameau does establish a clear hierarchy of functions in which are found:

a. two functions uniquely identified with specific degrees (tonique, dominante-tonique);

b. one ambivalent function found on two degrees (sous-dominante);

c. a versatile function which may appear on any other degree (the simple dominante).

By establishing a distinction between the simple dominante and the dominantetonique, and by limiting the uses of the sous-dominante to the first and fourth degrees, Rameau indeed maintains a unique connection between tonal context and chordal function.

\section{c. The Assessment of Harmonic Function}

Determining harmonic function is not merely a matter of stacking up thirds - "the tertian structure of chords" (p. 32) - but rather involves an examination of the context in which chords appear; in particular, the function is conditioned by the resolution of dissonances, therefore by what happens after. This explains why the "versatile function" chord in the list above is a dominant, never a tonic or subdominant. The function of this chord is determined by what follows it, not by some immanent quality or by its origin. As demonstrated earlier, neither the tonic 
nor the subdominant possess an inherent tension calling for resolution. If two successive chords are felt to be mutually complementary, the first of the pair is a dominante, never a tonic or subdominant.

When Dahlhaus writes that the dominante and sous-dominante are "chordal types requiring a specific resolution" (italics mine), he turns Rameau's concept upside down. It would have been more accurate to write that they are "chordal types acquiring a specific function by virtue of their resolution and of the corresponding root motion." In Rameau's perspective, function is not immanent to the chord, but determined a posteriori by virtue of the complementarity of the chord to which it moves. This is the only way one can account properly for situations where the chord of preparation does not contain the characteristic dissonance, and yet, moves to the chord of resolution. Retrospectively, the chord of preparation may be considered to be contextually "dissonant." In particular, one thinks of those instances where the dominant is a simple consonant triad, followed by a consonant triad on the tonic. The fact that the seventh is missing in the first chord does not prevent its identification as a dominant.

\section{Questionable Statements}

A few questionable statements are scattered throughout the book.

a. On pp. 34-35, Dahlhaus writes that "in Rameau's system, the factor that binds together the progression of chordal roots and the characterization of a key is the resolution of dissonances" (italics mine). But the quotation from Rameau that this phrase is meant to elucidate deals with chord connection by common tone not with the resolution of dissonances.

b. On p. 36, in interpreting a quotation from Sechter, Dahlhaus writes that "explaining the fourth degree as the 'most remote' does violence to common sense." In the passage quoted, however, Sechter does not say that the fourth degree is the most remote but that the root progression I-IV is the most remote. Indeed, it is centrifugal. In major, the "natural" mode whose progressions are paradigmatic, it is the only progression, other than $\mathrm{V}-\mathrm{I}$, involving two major triads, and therefore capable of mimicking a dominant-tonic progression, but in the wrong key. In all other root progressions by fifth, either the first triad is minor, forfeiting any interpretation of this chord as a dominant, or the second triad is diminished (vii), excluding a tonic interpretation.

c. In an analysis of the "Ave Maria" attributed to Josquin des Prés, on pp. 106-7, Dahlhaus is intrigued by the fact that the melody seems to be in $\mathrm{G}$ major, while the harmony is clearly in $\mathrm{C}$ major. He ignores the fact that in the passage quoted, the anonymous composer (Josquin arranged this work for six voices) quotes the hymn "Ave vera virginitas," of which this is the first phrase. Indeed, 
the hymn ends in $\mathrm{C}$ major. The argument that this fragment is evidence of an incipient preference for the I-IV-V-I harmonic progression is seriously weakened by the fact that the leading tone (given in the melody) does not move to the tonic.

d. Dahlhaus's view of the history of tuning systems is surprising. The following quotation is but the first of a number of similar statements: "Just intonation generally prevailed from the middle of the 16th century on, above all due to the authority of Zarlino" (p. 187). The standard view on this matter is well expressed by the article "Tuning" in the New Harvard Dictionary of Music: "By ca. 1650, it had been found simpler to ... adopt a temperament instead of a tuning" (p. 884). On the other hand, the "mean-tone" family of temperaments, which was favored in practice in the period under scrutiny, receives but passing attention by Dahlhaus.

e. Following an extensive and illuminating discussion on the influence of Zarlino's prototypal schema for the succession of clausulas (I-V-III-I), Dahlhaus writes:

Zarlino's I-V-III schema coincides not only with the norms of 16th-century practice ... but also with the key relationships in the minor mode of tonal harmony. In those 17 th- and 18th-century works whose harmonically tonal character cannot be doubted, the primary disposition of keys in minor is T-Tp-D-T. (p. 230)

The fact that the positions of V (D) and III (Tp) are inverted with respect to Zarlino's schema seems to have escaped the attention of the author.

f. In measure 8 of the madrigal, "O Mirtillo," by Monteverdi, there is a progression from an E major to a D major triad. In his analysis of this progression (p. 295), Dahlhaus presents three different explanations, none of which mentions the point most significant in my view: the $F$ in the alto line is made sharp in order to avoid an augmented fourth leap (from B to F natural).

\section{Translation and Typographical Presention}

Anybody who has attempted reading Dahlhaus in the German original will join me in praising Robert $\mathrm{O}$. Gjerdingen for the intelligibility and elegance of his translation. I would go so far as to write that the translation clarifies the original text, particularly in those instances where the translator has inserted explanatory words of his own (always carefully indicated by square brackets). Similarly, the insertion of technical terms in German, also in brackets, highlights nuances that are likely to be missed otherwise. 
Writing for readers steeped in the Riemannian system, Dahlhaus does not feel the need to elucidate its tenets in a systematic fashion but rather proceeds in a polemical fashion, pitting it against other approaches. Aware that some readers may not be familiar with this system, the translator has prefaced the book with a five page "Guide to the terminology of German harmony," undoubtedly a praiseworthy initiative.

In only one case do I feel the need to question the English terminology chosen by the translator. On p. 60, we read: "Riemann's theory must be understood as dogma: as an attempt to explicate the harmony of one epoch - the 17th through the 19th century - in terms of systematically coherent concepts." The term used by Dahlhaus is not "Dogma," whose meaning is virtually identical in both languages, but "Dogmatik" (p. 60, note 3). None of the standard definitions of the word "dogma" apply here, and, in contexts other than faith and morals, this word carries negative connotations to which Dahlhaus explicitly objects (p. 60). Even the word "Dogmatik" is used in an unusual sense, as confirmed by the fact that Dahlhaus feels the need to provide the reader with a definition. In my view, this is a clear case of unnecessary verbal inflation: an explication based on systematically coherent concepts is, quite plainly, a "theory."

In the original edition, quotations in languages other than German were simply reproduced in their language of origin. The translator is to be highly commended for the care he took in inserting, following the original text, a translation into English. When available, current English versions are used for this purpose, Gjerdingen contributing translations of his own in other cases. This colossal undertaking is virtually flawless. Of hundreds of quotations, I have found only two minor blemishes. On p. 78, the quotation from Pseudo-Franco would read more accurately as follows: "Concerning consonances, three are consonant per se and perfect, namely the unison, octave, and fifth; three are consonant per accidens [i.e., depending on the context], namely the minor and major thirds preceding the fifth or unison, and the major sixth preceding the octave." In note 17 , p. 260 , concerning Josquin, "defuit in plerisque modus" is translated as "as a rule he lacked moderation," rendering this quotation totally meaningless in context. A fitting translation would read: "in many instances, the mode is deficient."

Whether the translator or the author is to be held responsible for these, it is to be deplored that two references are missing. Allusion is made to the works of Carl Stumpf on pages 62 and 93, none of which carries a reference. The bibliography is also silent on that point.

Each chapter is partitioned into broad subdivisions under a general heading, and these subdivisions are themselves divided into sections. Further division is, unfortunately, inconsistent. Sections are usually separated by a string of aster- 
isks, and these subdivisions are frequently segmented into numbered paragraphs. However, the string of asterisks also appears between numbered paragraphs (e.g., p. 181); different numbering sequences appear within the same subdivision (see the section between pages 196 and 200); finally, paragraph numbering adopts a variety of styles (letters, numbers, and, occasionally, ordinal adjectives). In a book of this stature, a further level of subheadings, replacing the mute asterisks, would have been most welcome, and a consistent style of paragraph numbering should certainly have been adopted.

\section{Conclusion}

In musicology, as in other fields of applied intellectual endeavour, a theory may be looked at from two points of view: from its systematic and from its extensional sides. On the systematic side, the value of a theory lies in the significance of its primary axioms, on the one hand, and the logical elegance of the ensuing process, on the other. On the extensional side, the importance of a theory is found in the breadth of reality for which it accounts and the practicality of its methods. A theory always fares better on one side than on the other: some theories are remarkable primarily for their formal qualities, others for the mastery with which they account for broad segments of reality, while the rigour of their operations may be open to question. Because of their emphasis on a limited number of axioms, highly formalized theories are inclined to simple-mindedness. Extensional theories, on the contrary, are often felt to be muddle-headed.

The Riemannian system is an excellent example of a formally organized, but extensionally unsatisfactory theory: all too often, in applying his theory to the data of music history, Riemann must bend the facts to suit the pattern or ignore substantial evidence. As we have seen throughout this review, Dahlhaus is aware of some of these shortcomings and duly attempts revisions and reformulations, while leaving his fundamental allegiance unchallenged. There lies the great strength, as well as the basic weakness of this remarkable book: Dahlhaus is at his best in scrutinizing both the repertoire and the theory of pre-tonal music, putting each item of his extensive fresco in its proper musical and intellectual context; the portrait he draws of the tonal period, however, is sadly lacking, both from a theoretical and from an analytical point of view, because of his overreliance on Riemann, on the one hand, and of his limited understanding of Rameau and Fétis - not to mention his complete silence on Fux and other theorists of the contrapuntal tradition.

Over and above the various aspects which we have found to be wanting, however, this book leaves exposed a problem central to this, as well as to many other theorical ventures: tonality is dealt with as if it were the totality of music. 
Should it not be, rather, a tool in the service of a more inclusive phenomenon, a device subservient to the multifarious experience of our art? We theorists must be reminded, once in a while, that affirming tonality is NOT the goal and purpose of tonal music. In spite of its undeniable importance, tonality is but one of a set of tightly intertwined means put in the service of expressive ends. This issue, unfortunately, seldom surfaces. Very late in the book, Dahlhaus hints at what could be a suitable frame of reference for assessing harmonic and tonal features:

A harmonic analysis that neglects the other features of compositional technique would be incomplete even as an analysis of harmony. Many features of harmony stand out more clearly or only become recognizable at all when one studies the reciprocal relationships by which harmony is bound up with a composition's rhythm and form. (p. 297)

Upon reading the last page of this superb book, the reader may be left with the impression of having come full circle, but this circle ends at a much higher altitude than it started. Along the way, some stones may have been left unturned or turned the wrong way around. But these can easily be forgotten at the sight of the panorama unfolding before the mind's eye. Dahlhaus's guidance in scaling these heights must be acknowledged and Robert $O$. Gjerdingen is to be praised most heartily for making this monumental contribution accessible to the Englishspeaking public.

Paul Cadrin

George J. Buelow. Thorough-Bass Accompaniment according to Johann David Heinichen. Revised edition. Lincoln, Neb., and London: University of Nebraska Press, 1992. xvii, 462pp. ISBN 0-8032-6106-3 (pa)

In this volume and elsewhere, George J. Buelow has contributed a great deal to our understanding of German baroque theory and practice; he has been particularly interested in well-defined and focused studies of performance practice: "We need fewer publications on the thorough-bass that attempt to describe the practice for its entire two-hundred-year duration and more that concentrate on individual periods, countries, and generational solidifications of style". ${ }^{1}$ I could not agree more. His summary of and commentary on the ideas of Johann David

1 George J. Buelow, review of Figured Bass Accompaniment by Peter Williams, The Musical Quarterly 58 (1972): 313. 